\title{
Resource efficiency, circular economy and sustainability dynamics in China and OECD countries
}

\author{
Paul Welfens ${ }^{1} \cdot$ Raimund Bleischwitz $^{2}$ • Yong Geng ${ }^{3}$
}

Published online: 30 June 2017

C) Springer-Verlag GmbH Germany 2017

\section{Introduction}

Progress in the areas of sustainability and a circular economy is quite important for Europe, China and most other countries in the world economy: Putting a focus on resource efficiency and a circular economy offers a bottom-up industrial perspective on sustainability dynamics that could in fact become a new engine of green growth worldwide.

Global climate policy reached an international consensus at the Paris Climate Conference in 2015. It also reflects shifting responsibilities from international commitments towards coordinating nationally determined contributions. However, progress is at risk after US President Trump's declaration of intent to withdraw from the Paris Agreement. In fact, any international cooperation with the current US administration on climate policy appears rather difficult. Furthermore, the Trump administration seems to enter a conflict with the US scientific community. Most US climate researchers are apparently not supportive of a position visible in the Trump administration according to which industrialization and human behavior have not significantly contributed to global warming, and the policy steps envisaged in Paris would not help to achieve progress with the $2{ }^{\circ} \mathrm{C}$ goal, i.e. to prevent a critical increase in global temperatures compared to pre-industrialization in Europe.

The interesting angle for international economics now is the collective good dimension: Combatting global warming is of utmost relevance in international

Raimund Bleischwitz

r.bleischwitz@ucl.ac.uk

1 European Institute for International Economic Relations (EIIW), University of Wuppertal, Wuppertal, Germany

2 Institute for Sustainable Resources (ISR), University College London (UCL), London, UK

3 School of Environmental Science and Engineering, Shanghai Jiao Tong University (SJTU), Shanghai, China 
environmental policies since climate stabilization literally is a global public good - with all countries concerned there is naturally a broader problem in avoiding free-riding (and with the US retreating from the Paris Agreement in early 2017 there is a strong signal encouraging other free riders or would-be free riders). But does it mean climate action done at a national level or by individual actors doesn't yield private benefits? Evidence is robust on benefits stemming from energy efficiency and the like, and the markets for renewable energies and other eco-innovations are soaring worldwide. These benefits, actually: co-benefits, are at the heart of what we believe is the essence of resource efficiency and a circular economy.

Related innovation dynamics in specific markets are also pillars of international or supranational environmental policies. From an economic perspective key issues, however, concern market developments from local niches to international norms. Therefore it is quite important to make progress in the field of environmental-economic modeling with a clear resource angle, and to gain a better understanding of green innovation dynamics in selected sectors and countries.

Recycling and markets for secondary resources are major pillars of sustainable development. Governments in both OECD countries and China have emphasized the need to make progress with recycling and such new markets towards a circular economy. The European Commission has emphasized long-term perspectives too. At the same time it is yet to be seen how the manifold barriers can be overcome and new business models be created. Aspects of international trade deserve special attention as revenues stemming from exporting primary natural resources will be diminished, while markets for secondary materials will flourish in and around the consuming countries. However, other aspects such as the low recycling intensity of mobile phones in Europe, China and many other countries are relevant too.

Without doubt, China is quite a relevant player in all markets. Being on its way to become the world's largest economy, it also has become the largest user of natural resources and suffers severely from pollution. The Chinese response is an 'ecological civilisation', which includes the ramp up of renewable energies and cleantech as well as ambitions plans for a circular economy. Some observers now start to see China as leading a global green shift.

The extent to which China has started to shape those international green market dynamics, how these developments coincide with European efforts, and how future markets and international collaborations may look like are key aims of a research project. The Sino-European Circular Economy and Resource Efficiency (SINCERE) project develops new economic modelling tools to understand the resource use patterns of China and the EU. It also addresses indicators and metrics, institutions and policies, and it examines historical patterns. Being funded by five national research agencies from UK (ESRC), China (NSFC), Germany (DFG), France (ANR) and The Netherlands (NWO), it also opens up economic research to interdisciplinary endeavours with environmental engineering and industrial ecology.

This special issue highlights some of the research papers conducted through the SINCERE project. All have been subject to discussions internally and with an international advisory board. One of the Sino-German collaborative papers puts the focus not 
only on ETS developments in Europe and China's pilot regions but also emphasizes the changing ranking of countries in the EIIW-vita Global Sustainability Index which is a composite index in line with OECD requirements. China as well as several other countries have strong progress over time not only in the sub-index on green international competitiveness but also in the overall index - downloading that index and its Schumpeterian components is possible (with annual values for about 130 countries since 2000) from www.eiiw.eu.

The contribution of Matthew Winning, Alvaro Calzadilla, Raimund Bleischwitz, and Victor Nechifor- describes the development of the UCL Environmental Global Applied Computable General Equilibrium model (ENGAGE-materials) created to consider the economic and sectoral effects of potential policies on a circular economy and resource efficiency, which affect materials and resources at the stages of extraction, production and recycling. The authors' policy scope is global with a special emphasis on China and Europe, as both regions have dedicated policies in place and indicate their willingness to take the lead. The case of steel is relevant as it is a key material for all economies across the world and offers a range of interesting features for circularity and sustainability. ENGAGE-materials models iron ore mining, primary production of iron and steel, secondary production of iron and steel, and steel scrap recycling at the global level. This technology rich framework is utilized to provide preliminary results on scenarios comprising economic insights into a saturation effect and straightforward policy such as doubling the availability of secondary steel. Tentative results confirm the usefulness of the modelling and moderately positive impacts; yet more needs to be done to validate those results.

Rene Kemp, Eva Barteková and Serdar Türkeli scrutinize the innovation trajectory of eco-cement in the Netherlands by examining the innovation nexus of eco-cement manufacturers, scientists/researchers, waste producers and policymakers as part of a broader analysis of markets, policy and society, with special attention to standards and regulations. The influence of policy and innovation interactions are substantiated by policy documents, media news, patterns of eco-cement use, and in-depth interviews conducted with relevant eco-cement actors. The authors' analysis brings forward empirical evidence of how policymakers are involved in the innovation trajectory of eco-cement in multiple ways through building regulations, sector policies, waste policies, and science and innovation policies. Political economy aspects of regulation and innovation in cement industry (e.g. the cooperative approach of waste authorities with regard to re-use of waste, absence of policies to put a price on $\mathrm{CO}_{2}$ emissions from cement production) are being described, together with the specificities of the cement market. Bans on the disposal of fly ash and sewage sludge resulted in the use of those materials either as a supplementary cementitious material or a fuel. Demand for green cement is presently growing but meets with several obstacles. Carbon policies are shown to constitute a weak influence. Innovation in eco-cement co-evolved with policy, through mutual dependencies, as a theoretical finding for innovation studies.

The paper by Nan Yu is a pioneer study which examines the innovation of renewable energy generation technologies based on residential patent applications in 30 regions of China between 2006 and 2015. Wind power, solar energy, geothermal energy, ocean energy, hydro power, and biomass \& waste energy are the subject technologies for this analysis. Different indicators such as absolute numbers, growth rates and revealed technology advantages are used to measure the various green innovation dynamics in 
different regions. The results show that some regions with a higher number of patent applications or growth rates did not show stronger technological advantage (specialization) in such technologies. On the other hand, the region of Inner Mongolia shows a very strong specialization but with a much smaller number of patent applications.

Reaching the sustainable development goals needs innovations. The contribution of Rainer Walz, Matthias Pfaff, Frank Marscheider-Weidemann and Simon GlöserChahoud addresses the dynamics of green energy and resource efficiency innovations, and looks at the positioning of countries from the North and emerging economies. The authors use indicators for both general innovation capabilities, and specific green technology capabilities. Data on general innovation capabilities reveal that the traditional OECD countries, by and large, still possess advantages compared to Newly Industrializing Countries (NICs). Literature and patent indicators reveal that the innovation dynamics are particular high for publications. Literature and exports indicators reveal that the South has been catching up substantially. With regard to patents, some countries of the South are catching up, but the North is clearly leading. A detailed analysis of co-patenting and country-to-country trade data reveals a more differentiated picture: Leading countries from Europe such as Germany are still specialized on serving the markets of traditional OECD countries. Japan and Korea are very reluctant with regard to co-patenting, but specialize on exporting to China. South-South trade in green technologies is the fastest growing market segment. However, countries of the South are pursuing a differentiated strategy: Mexico is highly integrated into the US economy. Singapore and South Korea have been catching up and provide technologies especially for China. China itself is following a double strategy, with absorbing technology from the North in order to compete on markets of the North on the one hand, but increasingly specializing in becoming lead supplier for countries of the South on the other hand. The other technology providers from the South are mainly specializing on supplying other countries from the South. Thus, a segmentation of the market is likely, with low- to mid-tech green sustainability innovations in the South more likely originating in the South as well, and China being an important country to adapt knowledge from the North to the needs of the South.

Vladimir Udalov, Jens Perret and Veronique Vasseur analyze the impact of environmental motivations on the individual's decisions regarding investments in energy efficiency and the adoption of energy-saving habits on the basis of a representative online survey carried out in Belgium, Germany and the Netherlands. Various energy efficiency investments and daily energy-saving activities are considered. Accounting for endogeneity in the basic estimation model, in particular regarding energy conservation activities, the subject's experience with extreme weather events are used as an instrument for environmental motivations. The study provides empirical evidence that individual energy efficiency investments are generally driven by environmental motivations. Additionally, for the Dutch and the German sub-samples environmental motivations positively affect daily energy-saving activities. The findings suggest that policy programs aimed at raising environmental awareness and forming proenvironmental motivations can lead to an increase in energy efficiency investments and daily energy-saving activities.

The paper of Evgeniya Yushkova and Yunting Feng investigates the determinants of the intention to bring mobile phones for recycling based on data regarding the 
determinants of bringing mobile phones for recycling collected from university students in both the Chinese and German academia. Using structural equation modeling, the authors examine the direct and indirect effects of social norms, knowledge about the environmental benefits of recycling and a pro-environmental attitude on the intention to recycle mobile phones finding confirmation that attitude, social norms, and knowledge contribute positively and significantly to the intention to bring phones for recycling. As for three mediating effects tested, attitude mediates the relationship between knowledge and intention, as well as between social norms and intention. Knowledge as a mediator between social norms and attitude does not have a highly significant effect. Looking at the results of the Chinese and German sub-samples, Yushkova and Feng find that social norms have no direct effect on intention for the German sub-sample, but an indirect one through attitude. Knowledge has no significant effect for the German sub-sample. Results for the Chinese sub-sample indicate an indirect effect of social norms on attitude via knowledge, while knowledge itself has an indirect effect on intention through attitude.

Paul Welfens, Nan Yu, David Hanrahan and Yong Geng analyze the Emission Trading Schemes of China and the EU and show that China's envisaged national ETS could bring a major contribution in the international approach against global warming; new perspectives on the use of composite sustainability indicators are also highlighted. China's regional pilot schemes will converge to a (more) uniform price of emission allowances. As China is a major economic and political actor in the world economy, China's progress with ETS is important. At the same time, China's progress in the field of green international competitiveness - standing for a positive revealed comparative advantage in environmentally friendly goods - in the period 2000-2015 is considerable and the improved positioning of China in the EIIW-vita sustainability indicator shows considerable technological dynamics in Asia. The European ETS is working, but it suffers from the rather low price of emission allowances. The long-term time horizon of 2050 in the EU climate policy is rather ambitious and it is unclear whether or not a consistent G20 approach can be achieved with the EU, China, Japan and the US cooperating among each other. There is a lack of a specialized climate stabilization institution in the world economy, the traditional anchoring of climate policy in the UN weakens the practical pressure for efficient cooperation since the UN is very heterogeneous in terms of per capita income and GHG emissions per unit of GDP; G20 might be an institution that is suitable for effective policy cooperation. More initiatives in the field of recycling could be useful.

These papers will need to be discussed and embedded in a broader research agenda on the role of China in the future world economy, and unleashing ecoinnovations at an international scale. The international research project SINCERE hopefully stands for encouraging research collaboration and analytical progress in OECD countries and China. The many new findings should help to gain a better understanding of the manifold challenges and promising policy options. Certainly there is room for more transferring technologies and other innovations in both industry and society as well as across governments. To the extent that sustainable globalization is contributing to real per capita income convergence, the opportunities for enhanced cooperation and a broader 
consensus should grow since countries with similar per capita incomes have rather similar policy preferences - just as people with similar per capita incomes share rather similar preferences.

\section{Wuppertal, London and Shanghai}

\section{Paul JJ Welfens, Raimund Bleischwitz, Yong Geng}

Acknowledgements The authors acknowledge funding through the ESRC et al. funded SINCERE project (ES/L015838/1), the Natural Science Foundation of China (71325006, 71690241, 71461137008), the Shanghai Municipal Government (17XD1401800), the Fundamental Research Funds for the Central Universities through Shanghai Jiao Tong University (16JCCS04), as well as through Deutsche Foschungsgemeinschaft (DFG). More information about SINCERE: http://www.ucl.ac.uk/sincere/home. 